Schizophr Res. Author manuscript; available in PMC 2012 February 21.

Published in final edited form as:

Schizophr Res. 2007 September ; 95(1-3): 248-249. doi:10.1016/j.schres.2007.05.040.

\title{
Sibship characteristics in a familial sample with genetic susceptibility to schizophrenia
}

\author{
Janice A. Husted ${ }^{\star}$, \\ Department of Health Studies and Gerontology, University of Waterloo, Waterloo, Ontario, \\ Canada
}

Pete Driezen,

Population Health Research Group, Lyle S. Hallman Institute, University of Waterloo, Canada

Eva W.C. Chow, and

Clinical Genetics Research Program, Centre for Addiction and Mental Health, Toronto, Ontario, Canada, Department of Psychiatry, University of Toronto, Toronto, Ontario, Canada

\section{Anne S. Bassett}

Clinical Genetics Research Program, Centre for Addiction and Mental Health, Toronto, Ontario, Canada, Department of Psychiatry, University of Toronto, Toronto, Ontario, Canada

\section{Dear Editors}

In schizophrenia there has been a renewed interest in the role of sibship characteristics. It has been suggested that sibship characteristics may be markers of either prenatal or childhood exposures to infection, nutritional deficiencies or other stressors (Haukka et al., 2004; Pedersen and Mortensen, 2004; Smits et al., 2004; Westergaard et al., 1999). In this study we investigated whether birth interval and birth order were associated with schizophrenia in a familial form of schizophrenia. To our knowledge there is only one available study examining sibship characteristics in multiply affected families (ErlenmeyerKimling, 1969).

Twenty-one sibships with at least two affected members were recruited from 24 large families that demonstrate significant evidence for genetic linkage of narrowly defined DSMIII-R schizophrenia (schizophrenia or chronic schizoaffective disorder) to a locus on chromosome 1q22 (Brzustowicz et al., 2000). In total, there were 172 siblings, 58 with narrowly defined schizophrenia, 112 without schizophrenia, and 2 assigned an unknown diagnosis . All sibships were complete (biologic mothers through their reproductive period), sibship members were born to the same mother and father, and $90 \%$ of unaffected siblings were through the major risk period for schizophrenia ( $>40$ years old)

Birth order was calculated as 1 plus the number of children born to the same mother and father and who were alive at the child's birth . Birth interval between siblings was defined as number of years between the child and the nearest older sibling, categorized into the

*Corresponding author. Department of Health Studies and Gerontology, 200 University Avenue West, Waterloo, Ontario, Canada N2L 3G1. ,Tel.: +1 519888 4567x35129; fax: +1 519746 2510., jhusted@ healthy.uwaterloo.ca. 
following periods: $0<2$ years, $2<5$ years, and 25 years. We tested birth order effects using the Haldane and Smith Method (Haldane and Smith, 1948), recommended for multiply affected sibships and clustering of births of schizophrenic members using ErlenmeyerKimling's Method (Erlenmeyer-Kimling, 1969). We used generalized estimating equation models (Hanley et al., 2003) to estimate effect of birth interval between the nearest older sibling, adjusting for birth order, sex, year of birth, maternal and paternal history of schizophrenia and maternal and paternal age at birth.

Size of sibships ranged from 2 to 16 (median=11), with twelve (57\%) and 7 (33\%) sibships containing 2 and 3 affected siblings, respectively. The median age of affected and unaffected sibs was 56.6 years and 53.6 years, respectively. Nineteen (90\%) sibships contained both females and males. Table 1 shows the distribution of birth rank in siblings and schizophrenic status. We found no evidence of a birth order effect. The difference between the observed and expected mean birth ranks (6.64) did not exceed twice the standard error of the expected mean (110.94). Furthermore, we found no significant evidence of birth clustering of siblings with schizophrenia $\left(\chi_{(7)}^{2}=2.03, p=0.083\right)$.

Short birth interval ( $<2$ years) and intermediate birth interval $(2<5$ years) to the nearest older sibling was associated with a non-statistically significant increased risk of schizophrenia, relative to a long birth interval of 25 years (adjusted odds ratio $(\mathrm{aOR})(95 \% \mathrm{CI})=2.65(0.17$, $41.61)$ and aOR $(95 \% \mathrm{CI})=3.00(0.20,44.08)$, respectively). Results did not materially change when 8 infant deaths were included in these analyses.

In conclusion, our findings suggest that neither birth order nor birth clustering of affected siblings are indicators of either a unique or shared environmental exposure in familial schizophrenia, similar to Erlen-meyer-Kimling's findings in multiply affected families (Erlenmeyer-Kimling, 1969). The observed increased risk for schizophrenia associated with short birth interval, while consistent with others suggesting a role for early nutritional deficiencies or infections in causation (Smits et al., 2004; Westergaard et al., 1999), was statistically insignificant, possibly due to low statistical power.

\section{References}

Brzustowicz LM, Hodgkinson KA, Chow EWC, Honer WG, Bassett AS. Location of a major susceptibility locus for familial schizophrenia on chromosome 1q21-q22. Science. 2000; 288 (5466):678-682. [PubMed: 10784452]

Erlenmeyer-Kimling L. The problem of birth order and schizophrenia: a negative conclusion. Br J Psychiatry. 1969; 115 (523):659-678. [PubMed: 5806857]

Haldane JBS, Smith CA. A simple exact test for birth order effect. Ann Eugen. 1948; 14 (2):117-124. [PubMed: 18863975]

Hanley JA, Negassa A, Edwardes MD, Forrester JE. Statistical analysis of correlated data using generalized estimating equations: an orientation. Am J Epidemiol. 2003; 157 (4):364-375. [PubMed: 12578807]

Haukka JK, Suvisaari J, Lonnqvist J. Family structure and risk factors for schizophrenia: case-sibling study. BMC Psychiatry. 2004; 4:41. [PubMed: 15566576]

Pedersen CB, Mortensen PB. Sibship characteristics during upbringing and schizophrenia risk. Am J Epidemiol. 2004; 160 (7):652-660. [PubMed: 15383409] 
Smits L, Pedersen C, Mortensen P, van Os J. Association between short birth intervals and schizophrenia in the offspring. Schizophr Res. 2004; 70 (1):49-56. [PubMed: 15246463]

Westergaard T, Mortensen PB, Pedersen CB, Wohlfahrt J, Melbye M. Exposure to prenatal and childhood infections and the risk of schizophrenia: suggestions from a study of sibship characteristics and influenza prevalence. Arch Gen Psychiatry. 1999; 56 (11):993-998. [PubMed: 10565498] 
